\title{
Socio economic profile of direct seeded rice (DSR) farmers of Haryana
}

\author{
Anil Kumar Rohila*, B. S. Ghanghas, P. S. Shehrawat and Pawan Kumar \\ Department of Extension Education, CCS Haryana Agricultural University, Hisar-125004 (Haryana), INDIA \\ *Corresponding author. E-mail: anil_bhana@yahoo.com
}

Received: August 15, 2015; Revised received: January 7, 2016; Accepted: March 19, 2016

\begin{abstract}
The study has focused on socio economic profile, adoption level of Direct seeded rice (DSR) farmers and extension strategy to increase the adoption of DSR cultivation in Haryana (India). More than half of respondents $(51.66 \%)$ belonged to the middle age group 36-50 years and maximum 21.67 per-cent farmer qualification found metric. Majority of the farmers (50.83 per cent) had low level of socio-economic. Economic motivation of farmers was 70.83 per cent belonged to low to moderate level, whereas 67.5 per-cent of respondents belonged moderate to high innovation proneness. The overall adoption level of DSR technology was low to moderate, since 70 per-cent of respondents belonged to low to medium category.
\end{abstract}

Keywords: Adoption Level, Conventional method, Direct Seeded Rice, Socio economic status

\section{INTRODUCTION}

Rice (Oryza sativa L.) is the staple food of more than 70 per cent of the world population. It plays vital role in country's food security as well as providing livelihood to millions of rural households. India is the second largest producer of rice after China. The yield is almost at par in case of basmati group if crop is properly managed (Piggin et al., 2002). CCS Haryana Agricultural University, Hisar have recommended package of practices of DSR cultivation in the year 2012. Rice is grown on an area of 439.49 lakhs hectare with total production of 106.54 million tonnes, with productivity of $2424 \mathrm{~kg} / \mathrm{ha}$ (Annual Report, 2014-15).

Direct seeded rice (DSR) technique is becoming popular now a day, because it offers a very exciting opportunity to improve water and environmental sustainability. Direct-seeded rice (DSR) is feasible alternative with good potential to save water, reduce labour requirement, mitigation of greenhouse gases (GHGs) emission and adaptability to climate risks. The rising atmospheric concentrations of GHG threaten to have severe impacts on food production, natural ecosystem and human health (Mukteshawar and Shehrawat, 2015).

The Indian agriculture has changed during the past about 50 years mainly due to development of agricultural technologies. The introduction of improved and high yielding varieties, better cultivation practices, extended irrigation facilities, availability of other inputs such as fertilizers and pesticides, use of farm machinery, etc. have been the prime concern of every government for development of agriculture in India (Desai and Pujari, 2007).

Indian agriculture is presently faced challenge of feed- ing a billion plus population of the country with little scope for increasing the acreage. To promote agricultural growth the only option left is to increase productivity through optimum use of inputs and improved crop production technology like DSR.

Keeping in view of the above facts and importance of this technology towards sustainable production of rice for the country as a whole and Haryana (India) in particular, the study was conducted with the objectives; socio-economic-profile of DSR farmers, adoption level of package of practices recommended by CCS Haryana Agricultural University, Hisar (Haryana) and extension strategy to increase the adoption of DSR cultivation in Haryana (India).

\section{MATERIALS AND METHODS}

To collect the primary on socio economic traits of paddy farmer multistage sampling technique was applied. Among major rice producing states like Punjab, Haryana, Uttar Pradesh. The Haryana state was purposively selected being higher contribution to basmati export of countries. Four districts Yamuna Nagar, Kurukshetra, Karnal and Kaithal were selected due to maximum area under of these in these districts. From each district, one block with maximum area under DSR culture was selected viz. Sadhaura from Yamuna Nagar, Shahbad from Kurukshetra, Assand from Karnal and Pundri from Kaithal. Further two villages were selected from each block which have maximum DSR culture. From each village, 15 DSR farmers were selected randomly, who were growing rice in DSR culture, making a total of 120 farmer respondents. The data were collected with the help of well-structured and pretested interview schedule developed. The data 
were analyzed and tabulated after applying suitable statistical techniques like frequency and \% etc.

\section{RESULTS AND DISCUSSIONS}

The findings of the present study revealed that more than half of respondents ( 51.67 per cent) belonged to the middle age group (36-50 years) (Table 1), followed by 31.67 per-cent of them were young farmers (up to 35 years). As far as old age group is concerned, a minimum (16.66 per-cent) of respondents were of old age group (50 and above). Results indicate that vast majority of the farmers $(83.34 \%)$ belonged to productive age group i.e. up to 50 years. Data revealed that a majority of respondent interviewd $(71.66 \%)$ had acquired school education i.e. primary to higher secondary followed by 14.17 per-cent graduate, while only 13.33 per-cent illiterate who had no schooling and single farmer was post graduate. Since education is significantly correlation with harvesting the benefits of science and technology. To popularize a new technology the educated farmers should be contacted first for its easy acceptance and adoption. Results of present study in Table 2 concluded that a majority of farmers (72.5\%) belonged to low to moderate level of socioeconomic status. DSR being a new technology require technical skill for weed control as well as capital investment in specially design seed drill. So, initially the high socio economic status persons should targeted for its wider acceptance and adoption. Table 3 shows the result of present study that majority of farmers (37.5 per-cent) had low level of economic motivation followed by 33.33 per-cent with medium economic motivation, while remaining 29.17 per-cent farmers had high economic motivation. It can be concluded that a majority of farmers (70.83 per-cent) belonged to low to moderate level of economic motivation. It suggested that that for newer technology like DSR cultivation farmers are to be motivated for its adoption at larger scale by demonstrating its higher net profits. Table 4 indicated that majority of the respondents (39.17 percent) had medium level of innovative proneness followed by $32.5 \%$ with low level of innovativeness, while $28.33 \%$ farmers belonged to high level of innovative proneness category. It concluded that 67.5 percent of farmers had moderate to high innovative proneness meaning thereby that newer technology was ac- ceptable to them so for its establishment in the field proper demonstrations and training are required. Result of present study regarding overall adoption level of DSR cultivation technology in Table 5 narrate that majority of farmers $(35.83 \%)$ belonged to low level of adoption followed by $34.17 \%$ medium adoption level and $30 \%$ with high level of adoption. So, only $70 \%$ of farmers had low to medium level of adoption means i.e. farmers had not adopted the full package of practices recommended by the university. Only 27.5 percent had fully adopted. The study gets support from Kaur et al. (2011) reported that considering the need of more technical knowledge for the adoption of DSR technology, the government should organize training programme for skill development and Singh et al. (2013) reported that farmers don't have full knowledge of scientific cultivation practices regarding scientific rice cultivation.

Extension strategy to increase the adoption of DSR cultivation in Haryana (India): Present study indicated that overall adoption of DSR farmers belonged to low to moderate adoption category. More hands on trainings and result demonstrations on farmers' fields with active participation of extension workers should be organized to update their knowledge as well as skills for establishment of DSR on their farms and success stories of high profit achievers of this technology should be widely published to motivate other farmers. Wide fluctuations of prices, lack of storage facilities and lack of minimum support price in case of basmati rice were perceived very serious constraints by the farmers (Oudhia, 1999). So, government should make stable policy regarding the procurement, fixing minimum support price and storage infrastructure at village level to ensure national food security as well sustainable and profitable farming of such export-oriented food grain. There should be fixation of minimum support price by government on the basis of Swami Nathan report which has recommended double price of produce to the cost of production incurred by the farmers. Govt. should make provision of subsidy on seed drill or low interest rate credit to purchase inputs and machinery, etc. for DSR cultivation and promote such type of resource conserving technology. Technical knowledge of extension functionaries should be updated for greatest success of DSR for sustainable food

Table 1. Profile of DSR farmers $(n=120)$.

\begin{tabular}{lllll}
\hline S. N. & Variables & Category & Frequency & \%age \\
\hline 1. & Age & Young (up to 35 years) & 38 & 31.67 \\
& & Middle (36-50 years) & 62 & 51.67 \\
& & Old (above 50 years) & 20 & 16.66 \\
2. & Education & Illiterate & 16 & 13.33 \\
& & Primary & 16 & 13.33 \\
& Middle & 26 & 21.67 \\
& & Metric & 25 & 20.83 \\
& & Higher Secondary & 19 & 15.83 \\
& & Graduate & 17 & 14.17 \\
& & Post Graduate & 1 & 0.83 \\
\hline
\end{tabular}


Table 2. Socio-Economic-Status of DSR farmers $(n=120)$.

\begin{tabular}{llll}
\hline Variables & Category & Frequency & \%age \\
\hline Socio- & Low (17-27) & 61 & 50.83 \\
economic- & Medium (27-30) & 26 & 21.67 \\
status & High (31-42) & 33 & 27.50 \\
\hline
\end{tabular}

Table 3. Economic motivation of DSR Farmers $(n=120)$.

\begin{tabular}{llll}
\hline Variables & Category & Frequency & \%age \\
\hline & Low (28-36) & 45 & 37.50 \\
Economic & Medium (36-40) & 40 & 33.33 \\
motivation & High (40-42) & 35 & 29.17 \\
\hline
\end{tabular}

production. Government/non-govt. organization should promote the establishment of producer companies in the area which will not only solve their problem of non -availability of quality seed but also help in getting higher returns by exporting their produce. New molecules of herbicides efficient in controlling complex weed flora for solving the problem of weed infestation should be provided to the farmers.

\section{Conclusion}

DSR being a novel and feasible alternative to conventional method, the extension agencies can best use the farmers with high innovativeness economic motivation, socio economic status and education status to establish such resource like technology in the field for sustainable food security of the country. Different dimensions of socio-economic profile of farmers indicated that vast majority of respondent belonged to productive age group (up to 50 years) while 71.65 per cent of respondents had acquired schooling education up to higher secondary. Majority of respondents belonged to low to moderate level of economic status. Regarding economic motivation of farmers, $70.83 \%$ belonged to low to moderate level of motivation and $67.5 \%$ of respondents had moderate to high innovation proneness meaning thereby that DSR was acceptable to them. The overall adoption of DSR technology was low to moderate. The promotion and establishment of such technology in the field is very essential for harnessing
Table 4. Innovation Proneness of DSR Farmers $(n=120)$.

\begin{tabular}{llll}
\hline Variables & Category & Frequency & \%age \\
\hline & Low (10-11) & 39 & 32.50 \\
Innovation & Medium (11-13) & 47 & 39.17 \\
Proneness & High (13-15) & 34 & 28.33 \\
\hline
\end{tabular}

Table 5. Overall adoption level of DSR Farmers ( $\mathrm{n}=120)$.

\begin{tabular}{llll}
\hline S. N. & Adoption level & Frequency & \%age \\
\hline 1. & Low (38-43) & 43 & 35.83 \\
2. & Medium (44-47) & 41 & 34.17 \\
3. & High (47-51) & 36 & 30 \\
\hline
\end{tabular}

greater benefits of this eco-friendly and resource conservation technology to have a sustainable food production system ensuring food security and enhancement of farmers' income.

\section{REFERENCES}

Annual Report (2014-15). Directorate of Agricultural and Cooperation, Ministry of Agriculture, Government of India.

Desai, B.K. and Pujari, B.T. (2007). Sustainable Agriculture: A vision for future, New Delhi Publishing Agency, New Delhi.

Kaur, M., Mahal, A.K. and Sekhon, M.K. (2011). Adoption of Labour-saving Technology in Paddy TransplantationMicro-Level Evidences from Punjab. Agricultural Economics Research Review, 24:568.

Mukteshawar, R. and Shehrawat, P.S. (2015). Farmers' awareness and perception towards greenhouse gases (GHG) emission. Annals of Biology, 31(1): 141-146.

Oudhia, O. (1999). Chhattishgarh Farmers response in control of weeds in Direct seeded rice. Agric. Sci. Digest. 19(4): 261-263.

Piggin, C.M., Garcio and Janiya, J.D. (2002). Establishment of irrigated rice under zeroconventional tillagesystem in Philippines.In International workshop on Herbicide Resistance Management and Zero Tillage in Rice Wheat Cropping, System, ed. by R.K.Malik, R.S.Balyan, A.Yadav and S.K.Bahwa. CCS HAU, Hisar India, 4-6 March, 2002. pp. 190-195.

Singh, R., Hansra, B.S. and Chand, R. (2013). Knowledge and Adoption Level of Farmers of Haryana about Scientific Rice Cultivation Practices. Journal of Community Mobilization and Sustainable Development, 8(1): 24-28. 